\title{
Preliminary Pharmacognostical and Phytochemical Screening of DiaKure-A Polyherbal Antidiabetic Formulation
}

\author{
Ujwala TK ${ }^{1}$, Sandra Celine ${ }^{1}$, Shawn Tomy ${ }^{1}$, Arulraj P², Sam Johnson Udaya Chander $\mathrm{J}^{3^{*}}$ \\ 'Pharm D Intern, RVS College of Pharmaceutical Sciences, Coimbatore, Tamil Nadu, INDIA. \\ 2Department of Biotechnology, RVS College of Pharmaceutical Sciences, Coimbatore, Tamil Nadu, INDIA. \\ 3Department of Pharmacy Practice, RVS College of Pharmaceutical Sciences, Coimbatore, Tamil Nadu, INDIA.
}

\begin{abstract}
Background: Diakure is an indigenously prepared hypoglycemic polyherbal formulation, containing mixture of Vetiveria zizanoides (root), Hemidesmus indicus (rhizome), Strychnos potatorum (seed), Salacia reticulata (bark), Holarhena antidysenterica (seed), Cassia auriculata (bark), Trigonella graecum (seed) and Acacia catechu (bark) and each individual herb has scientific background in treating diabetes. This study aimed to perform pharmacognostical evaluation, preliminary phytochemical evaluation, standardization, heavy metal analysis, pesticidal residual analysis and antimicrobial assay of DiaKure. Materials and Methods: $100 \mathrm{~g}$ of the powder mixture of all eight herbs mentioned above was boiled with $900 \mathrm{ml}$ water for $30 \mathrm{~min}$ to produce the polyherbal mixture and this mixture was used for performing various tests. Results: Organoleptic characters and macroscopic characters such as colour, odour, taste, size and shape are evaluated under pharmacognostical evaluations and ash values, extractive values and loss on drying are considered under standardisation parameters and are reported. Phytochemical screening of the extract revealed the presence of alkaloids, tannins, saponins, flavonoids, steroids, glycoside and sugars. The formulation has normal limits of heavy metal and pesticidal
\end{abstract}

residue. Also, the aqueous mixture, during its antimicrobial assay, does not exhibit any antibacterial or anti-fungal activities. Conclusion: The result of this study validates the use of aqueous extract of DiaKure in ethnomedicine, favouring the isolation of antidiabetic agents from the extract of DiaKure. Since the study was conducted in a controlled and authenticated manner, all the evaluation measures used in the study can be used for the standardization of the above-said formulation.

Key words: Polyherbal Formulation, DiaKure, Phytochemical, Antimicrobial, Antidiabetic, Standardization.

Correspondence :

Sam Johnson Udaya Chander J,

Asst. Professor, Department of Pharmacy Practice, RVS College of Pharmaceutical Sciences, Coimbatore, Tamil Nadu, INDIA.

Phone no: +919894676716

E-mail: mail2samjohnson@gmail.com

DOI: 10.5530/jyp.2016.4.14

\section{INTRODUCTION}

Plants are the gift of nature. A number of plants have been evaluated for their therapeutic potentials and are found to be active against various diseases. The secondary metabolites, especially the bioactive compounds present in the plants, provided the basis for several sophisticated traditional medicine systems like Ayurveda, Unani, Folk, and Chinese. ${ }^{1}$ Most of the herbal drugs have one or more active ingredients which is derived from the aerial and non-aerial parts, juices, resins, and oils of the plant. ${ }^{2,3}$ Because of the characteristic pharmacological activity, the phytomedicines (can be plants, parts of plants, and isolated bioactive compounds) have been used to treat or prevent various disorders. ${ }^{4,5}$ Effectiveness of the natural products, mainly the herbal extracts with their proven potential to cure diseases and negligible side effects in therapeutics, has already replaced the synthetically-derived chemical substances as in modern allopathic medication system, which is regarded as unsafe to human and environment. ${ }^{6}$

Diabetes mellitus (DM) is a metabolic disease characterized by high levels of blood glucose due to deficiency of circulatory insulin levels. ${ }^{7} \mathrm{DM}$ affects at least 15 million people globally. ${ }^{8}$ Currently available therapy for diabetes includes insulin and various oral hypoglycemic agents such as sulfonylureas, metformin, glucosidase inhibitors, etc., but these are reported to produce serious adverse side effects such as liver problems, lactic acidosis and diarrhea. ${ }^{9}$ Hence, there is a need of safe and potent antidiabetic drug from natural sources. The purpose of the present study was to perform preliminary phytochemical analysis and to investigate for antimicrobial activity of poly herbal formulation DiaKure, which may lead to find a more effective agent for treating diabetes and managing associated other infections.

\section{MATERIALS AND METHODS}

\section{Plant Material}

All the plant materials used in the study were collected from herbal store and botanical garden of Ayurveda Medical College, Coimbatore. Individual drugs were identified and authenticated by comparison with herbarium specimens at Tamil Nadu Agricultural University Coimbatore.

\section{Chemicals, Drugs and Instruments}

All the chemicals were collected from Ponmani and Co, Coimbatore. Other important chemical used in phytochemical analysis and antibiotic sensitivity like alcohol, agar, nutrient agar, hydrochloric acid, $\infty$-napthol, Sulphuric acid, Fehling A \& B, Benedict reagent, sodium hydroxide, nitric acid, ammonia, lead acetate, ninhydrin, sudan red III reagent, glycerin, picric acid, chloroform, acetic anhydride, ferric chloride, zinc, Dragendroff's reagent, Wagner's reagent, Mayer's reagent, sodium chloride and bromine water were collected from the store of RVS College of Pharmaceutical Sciences. All the chemicals used in the study were of analytical grade.

\section{Formulation of DiaKure}

All the below mentioned crude drugs in Table 1 were purchased with standard quality and washed carefully to avoid chances of foreign materials. Washed herbal drugs were allowed to dry under shade. Individual crude drugs were coarsely powdered and blended in equal proportions. The powdered formulation was kept in airtight containers to avoid the chances of moisture exposures. 


\section{Pharmacognostical Evaluation}

Organoleptic Evaluation:

The Organoleptic properties such as colour, odor, and taste of Vetiveria zizanoides, Hemidesmus indicus, Strychnos potatorum, Salacia reticulata, Acacia catechu, Holarrhena antidysenterica, Cassia auriculata and Trigonella graecum were evaluated and reported. ${ }^{10}$

\section{Macroscopical Evaluation}

The macroscopical studies such as size and shape of Vetiveria zizanoides, Hemidesmus indicus, Strychnos potatorum, Salacia reticulata, Acacia catechu, Holarrhena antidysenterica, Cassia auriculata and Trigonella graecum were evaluated and reported.

\section{Standardization Parameters}

Determination of total ash value involving acid insoluble and water insoluble ash value, ${ }^{11}$ extractive values, ${ }^{12}$ loss on drying, ${ }^{13}$ and stability studies ${ }^{14}$ were done according to the pre-existing procedures.

\section{Phytochemical Analysis}

DiaKure as well as individual constituents used in the formulations were subjected to systematic qualitative tests for identification of various plant constituents like carbohydrates, amino acids, proteins, glycosides, fats, oils, phenolic compounds, tannins, saponins, steroids, flavanoids and alkaloids with reference to standard procedures listed in Table 2 in accordance with Trease and Evans ${ }^{15}$ and Harborne ${ }^{16}$ with little modification.

\section{Heavy Metal Analysis}

$50 \mathrm{mg}$ of shade dried, sieved individual crude drug were mixed with $10 \mathrm{ml}$ of concentrated $\mathrm{HNO}_{3}, 4 \mathrm{ml}$ of $60 \%$ perchloric acid and $1 \mathrm{ml}$ of concentrated $\mathrm{H}_{2} \mathrm{SO}_{4}$, and the contents were kept undisturbed overnight. It was heated on a hot plate containing concentrated $\mathrm{H}_{2} \mathrm{SO}_{4}$ in a beaker, until the brown flame ceased coming out and allowed to cool. After cooling it was filtered through What mann's No. 42 filter paper and the filtrate was made up to $100 \mathrm{ml}$ using distilled water.

Pesticidal Residual Analysis: Pesticidal analysis was conducted to find out the presence of organophosphorus and chlorinated residues using method described by Kandasamy et al. ${ }^{17}$

\section{Antimicrobial Analysis} Sample preparation

Hot water extract of DiaKure at two different concentrations are prepared $(0.1 \& 0.2 \mathrm{mg} / \mathrm{ml})$

\section{Antibacterial Activity Media}

Nutrient Agar: Suspend $28 \mathrm{~g}$ of nutrient agar in $1 \mathrm{~L}$ of distilled water. Heat to boiling to dissolve the medium completely. Autoclave the dissolved mixture at 121 degree Celsius for 15 minutes and allows to cool but not to solidify. Pour nutrient agar into each plate and leave the plates on the sterile surface.

\section{Organism}

Staphylococcus, Streptococcus, E. coli, and Klebsiella.

\section{Control}

Positive control: Ampicillin, Gentamicin

Negative control: Water

\section{Antifungal Activity \\ Media}

Muller Hinton Agar Media: Take beef (3 g/l), Casein (17.5 g/l), Infusion starch (1.5 g/l), Peptone H Agar (17 g/l). Suspend $38 \mathrm{~g}$ of this medium in $1 \mathrm{~L}$ of distilled water. Mix well and heat with frequent agitation. Boil for 1 minute and sterilize at $121^{\circ} \mathrm{C}$ for 15 minutes. Cool to $40-45^{\circ} \mathrm{C}$ and pour into petridish.

\section{Organism}

Aspergillus, Penicillin

\section{Control}

Positive control: Fluconazole

Negative control: Water

Table 1: Names of the herbs and their families present in DiaKure

\begin{tabular}{cc}
\hline Botanical name & Family name \\
\hline Vetiveria zizanoides & Graminaceae \\
Hemidesmus indicus & Asclepiadaceae \\
Strychnos potatorum & Loganaceae \\
Salacia reticulata & Hippocrateacea \\
Acacia catechu & Mimosoidaceae \\
Holarrhena antidysenterica & Apocyanaceae \\
Cassia auriculata & Caesalpiniaceae \\
Trigonella graecum & Fabaceae \\
\hline
\end{tabular}

Table 2: Phytochemical tests done with individual constituents and DiaKure

\begin{tabular}{cc}
\hline Test & Methods Used \\
\hline ALKALOIDS & Dragendroff's test, Wagner's test, Mayer's test \\
FLAVANOID & Sulphuric acid test \\
STEROIDS & Liebermann Burchard test, Salkowaski test \\
SAPONINS & Foam Test \\
PHENOLIC COMPOUNDS \& TANNINS & Bromine Water Test \\
FATS \&OILS & Sudan Red III reagent Test \\
GLYCOSIDES & Keller-killiani Test \\
PROTEIN & Biuret test, Xanthophoretic test, Lead acetate test \\
CARBOHYDRATES & Molisch test, Fehling test, Benedict's test \\
AMINO ACIDS & Ninhydrin test \\
\hline
\end{tabular}


Table 3: Organoleptic character of individual constituents and DiaKure

\begin{tabular}{cccc}
\hline Drug & \multicolumn{3}{c}{ Organoleptic character } \\
\cline { 2 - 4 } & Colour & Odour & Taste \\
\hline Vetiveria zizanoides & Yellowish Brown & Aromatic / Pleasant & Aromatic \\
Hemidesmus indicus & Brownish Yellow & Aromatic / Pleasant & Bitter \\
Strychnos potatorum & Creamish yellow & Pleasant & Bitter \\
Salacia reticulate & Light brown & Characteristic & Mucilaginous \\
Acacia catechu & Brownish & Characteristic & Astringent \\
Holarrhena antidysenterica & Slight Yellowish & Pleasant & Characteristic \\
Cassia auriculata & Brown & Odourless & Characteristic \\
Trigonella graecum & Yellow & Characteristic & Mucilaginous \\
DiaKure & Brown coloured & Aromatic & Aromatic \\
\hline
\end{tabular}

Table 4: Microscopic character of individual constituents and DiaKure

\begin{tabular}{|c|c|c|}
\hline \multirow[t]{2}{*}{ Drug } & \multicolumn{2}{|c|}{ Microscopic character } \\
\hline & size & shape \\
\hline Vetiveria zizanoides & $1.5-3.0 \mathrm{~mm}(\mathrm{~b})$ & Twisted \\
\hline Hemidesmus indicus & $4.23-5.0 \mathrm{~mm}(\mathrm{l}), 1.21-2.0 \mathrm{~mm}(\mathrm{~b})$ & Cylindrical \\
\hline Strychnos potatorum & $10-22 \mathrm{~mm}(\mathrm{l}), 6-9 \mathrm{~mm}(\mathrm{w})$ & Ellipsoid \\
\hline Salacia reticulate & 25-30 mm (l), 10-14 mm (b). & Irregular and rough \\
\hline Acacia catechu & $2.0-4.0 \mathrm{~cm}(\mathrm{l}), 5.0-8.0 \mathrm{~mm}(\mathrm{~d})$ & Irregular \\
\hline Holarrhena antidysenterica & $2-3 \mathrm{~cm}(\mathrm{l}), 0.5-1.0 \mathrm{~cm}(\mathrm{~b})$ & Elongated \\
\hline Cassia auriculata & $22-26 \mathrm{~mm}(\mathrm{l}), 15-18 \mathrm{~mm}(\mathrm{~d})$ & Rough and irregular \\
\hline Trigonella graecum & $10-30 \mathrm{~mm}(\mathrm{l}), 5-15 \mathrm{~mm}(\mathrm{~b})$ & Rhomboidal \\
\hline
\end{tabular}

Table 5: Ash values of individual constituents and DiaKure

\begin{tabular}{cccc}
\hline Drug & \multicolumn{3}{c}{ Ash values } \\
\cline { 2 - 4 } & Total ash & Acid insoluble & Water insoluble \\
\hline Vetiveria zizanoides & $6.33 \% \mathrm{w} / \mathrm{w}$ & $0.66 \% \mathrm{w} / \mathrm{w}$ & $4.83 \% \mathrm{w} / \mathrm{w}$ \\
Hemidesmus indicus & $4.23 \% \mathrm{w} / \mathrm{w}$ & $1.15 \% \mathrm{w} / \mathrm{w}$ & $2.23 \% \mathrm{w} / \mathrm{w}$ \\
Strychnos potatorum & $3.0 \% \mathrm{w} / \mathrm{w}$ & $1.25 \% \mathrm{w} / \mathrm{w}$ & - \\
Salacia reticulate & $4.43 \% \mathrm{w} / \mathrm{w}$ & $1.39 \% \mathrm{w} / \mathrm{w}$ & $0.89 \% \mathrm{w} / \mathrm{w}$ \\
Acacia catechu & $2.80 \% \mathrm{w} / \mathrm{w}$ & $0.40 \% \mathrm{w} / \mathrm{w}$ & $1.60 \% \mathrm{w} / \mathrm{w}$ \\
Holarrhena antidysenterica & $4.61 \% \mathrm{w} / \mathrm{w}$ & $0.60 \% \mathrm{w} / \mathrm{w}$ & $6.67 \% \mathrm{w} / \mathrm{w}$ \\
Cassia auriculata & $3.56 \% \mathrm{w} / \mathrm{w}$ & $6.65 \% \mathrm{w} / \mathrm{w}$ & $0.71 \% \mathrm{w} / \mathrm{w}$ \\
Trigonella graecum & $3.3 \% \mathrm{w} / \mathrm{w}$ & $0.4 \% \mathrm{w} / \mathrm{w}$ & $1.6 \% \mathrm{w} / \mathrm{w}$ \\
DiaKure & $6.19 \% \mathrm{w} / \mathrm{w}$ & $3.21 \% \mathrm{w} / \mathrm{w}$ & $1.02 \% \mathrm{w} / \mathrm{w}$ \\
\hline
\end{tabular}

Table 6: Water soluble extractive value and Loss on drying of individual constituents and DiaKure

\begin{tabular}{ccc}
\hline Drug & Water extractive value & Loss on drying \\
\hline Vetiveria zizanoides & $14.20 \% \mathrm{w} / \mathrm{w}$ & $11.12 \% \mathrm{w} / \mathrm{w}$ \\
Hemidesmus indicus & $13.98 \% \mathrm{w} / \mathrm{w}$ & $2.1 \% \mathrm{w} / \mathrm{w}$ \\
Strychnos potatorum & $12.68 \% \mathrm{w} / \mathrm{w}$ & $8.70 \% \mathrm{w} / \mathrm{w}$ \\
Salacia reticulate & $6.95 \% \mathrm{w} / \mathrm{w}$ & $6.54 \% \mathrm{w} / \mathrm{w}$ \\
Acacia catechu & $12.0 \% \mathrm{w} / \mathrm{w}$ & $7.15 \% \mathrm{w} / \mathrm{w}$ \\
Holarrhena antidysenterica & $33.51 \% \mathrm{w} / \mathrm{w}$ & $2.74 \% \mathrm{w} / \mathrm{w}$ \\
Cassia auriculata & $10.03 \% \mathrm{w} / \mathrm{w}$ & $7.7 \% \mathrm{w} / \mathrm{w}$ \\
Trigonella graecum & $9.7 \% \mathrm{w} / \mathrm{w}$ & $12.62 \% \mathrm{w} / \mathrm{w}$ \\
DiaKure & $6.19 \% \mathrm{w} / \mathrm{w}$ & $7.8 \% \mathrm{w} / \mathrm{w}$ \\
\hline
\end{tabular}


Table 7: Phytochemical evaluation reports

\begin{tabular}{cccccccccccc}
\hline Chemical constituents & V.Z & H.I & C.A & A.C & H.A & T.F & S.P & S.R & DK \\
\hline ALKALOIDS & + & + & + & + & + & + & + & - & + \\
FLAVANOID & + & + & - & + & + & + & + & - & + \\
STEROIDS & - & + & + & - & - & + & - & + & + \\
TANNINS & + & + & + & + & + & + & - & - & + \\
SAPONINS & + & - & - & + & + & + & + & - & + \\
PHENOLIC COMPOUNDS & - & + & - & + & - & + & + & - & + \\
FATS \&OILS & + & - & - & - & + & - & - & - & + \\
GLYCOSIDES & + & - & + & + & + & + & + & + & + \\
PROTEIN & - & + & + & - & + & - & + & - & + \\
CARBOHYDRATES & + & + & + & + & + & - & + & + & + \\
AMINO ACIDS & - & + & - & - & + & + & + & - & + \\
REDUCING SUGAR & - & + & - & - & + & - & - & + \\
\hline
\end{tabular}

(+) -Present, (-) -Absent, V.A-Vetiveria zizanoides, H.I-Hemidesmus indicus, S.P-Strychnos potatarum, S.R-Salacia reticulata, A.C-Acasia catechu, H.A-Holarhena antidysenterica, T.F-Trigeonella foenum, C.A-Cassia auriculata.

Table 8: Heavy metal analysis of DiaKure

\begin{tabular}{ccc}
\hline \multirow{2}{*}{ Heavy Metals } & Allowable Limits & $\begin{array}{c}\text { Content present } \\
\mu \mathrm{g}\end{array}$ \\
\hline Arsenic & 1.5 & 0.5 \\
Chromium & 15 & 3.0 \\
Iron & 1500 & 322 \\
Lead & 1.0 & 0.3 \\
Mercury & 1.5 & 0.5 \\
Zinc & 1500 & 365 \\
\hline
\end{tabular}

Cup plate method and filter paper disc method ${ }^{18}$ was used in antimicrobial assay under strict standard laboratory setting maintained with aseptic conditions.

\section{RESULTS}

\section{Organoleptic evaluation:}

The Organoleptic properties such as colour, odur and taste of Vetiveria zizanoides, Hemidesmus indicus, Strychnos potatorum, Salacia reticulata, Acacia catechu, Holarrhena antidysenterica, Cassia auriculata, Trigonella graecum and DiaKure were evaluated and reported in Table 3.

\section{Macroscopical evaluation:}

The macroscopical studies such as Size and Shape of Vetiveria zizanoides, Hemidesmus indicus, Strychnos potatorum, Salacia reticulata, Acacia catechu, Holarrhena antidysenterica, Cassia auriculata, Trigonella graecum and DiaKure were evaluated and reported in Table 4.

\section{Ash values}

a. The total ash values of DiaKure and individual components were found out and reported in Table 5.

b. The acid insoluble ash values of DiaKure and individual components were found out and reported in Table 5 .

c. The water insoluble ash values of DiaKure and individual components were found out and reported in Table 5.

\section{Extractive values:}

The water soluble extractive values of DiaKure and individual components were found out and reported in Table 6.

\section{Loss on Drying}

The loss on drying values of DiaKure and individual components were found out and reported in Table 6.

\section{Stability Studies}

The stability studies were carried out and inferred that the formulations showed no signs of instability under any off the different temperature conditions maintained during the study.

\section{Phytochemical Evaluation}

Phytochemical screening of the extract revealed the presence of alkaloids, tannins, saponins, flavonoids, steroids, glycoside and sugars, detailed report is described in Table 7 .

\section{Heavy Metal Analysis}

Data obtained from the study indicated that the content of heavy metals in the polyherbal formulation DiaKure was found to be within the limits as per I.P.

\section{Pesticidal Residual Analysis}

Data obtained from the Pesticidal residual analysis indicates that the organophosphorus and the chlorinated pesticides present in the Polyherbal formulation DiaKure were found to be within the limits as per I.P.

\section{Antimicrobial Sensitivity Test}

The formulated drug DiaKure fails antimicrobial sensitivity test. Both cup plate method and filter paper disk method gave negative results for antibacterial and anti-fungal activity tests.

\section{DISCUSSION}

Standardization is a vital step in establishing the quality and/or efficacy of any polyherbal formulations. Acceptance of indigenously prepared herbal products depends on their standard quality control profiles, which is often unavailable ${ }^{17}$ and hence WHO has suggested certain methods for the standardization of herbal drugs which include microscopic and macroscopic evaluation and also its chemical profiling. Organoleptic evaluation like shape, size, colour, texture, odour and taste parameters were evaluated for macroscopical evaluation. Comparative microscopic evaluation of powdered herbal drug, ash values, extractive values, loss 
on drying, and physical characteristics of polyherbal formulations $\mathrm{s}^{18-20}$ were used for microscopical evaluation. Some advanced methods like chromatographic, spectrophotometric or combination of these, polarography, electrophoresis, and use of molecular biomarkers are currently used in standardization of herbal drugs. ${ }^{21-26}$ The formulation was powder in nature and has characteristic odour and colour. Standardization of polyherbal formulation as per pharmacopeia was carried out based on the physiochemical parameters and the DiaKure passed all the tests. DiaKure was also found to be stable. As the physical characteristics and organoleptic evaluation of a formulation are important parameters for determining adulteration with other related species or for authentication, purity and efficacy when compared with standard values, the results of our formulation are quite encouraging where it is proved to be pure and is stable. The DiaKure has less moisture content and less value of moisture content could prolong stability of prepared formulation by preventing the growth of microorganism.

Herbal formulation are usually rich in phytoconstituents like phenols, flavonoids, terpenoids, coumarins, etc., which exhibits blood glucose reduction. ${ }^{27-29}$ Preliminary phytochemical analysis was carried out as per the standard procedure and DiaKure indicated the presence of phytochemical metabolites like flavanoid, steroid, tannins, saponin, phenolic compounds, fats \& oils, glycosides, protein, carbohydrates, amino acids, reducing sugar. All the plants studied showed the presence of alkaloids except Salacia reticulata, but the plant gave positive results for steroid, glycoside and carbohydrate. Fats \& Oils and Reducing sugar were absent in many of the plants. The DiaKure showed positive result for the presence of Alkaloids, Flavonoids, Steroids, Tannins, Saponins, Phenolic compounds, Fats \& Oils, Glycoside, Protein, Carbohydrate, Amino acid and reducing sugar.

Pesticidal residual analysis showed that the organophosphorus and the chlorinated pesticides present in the polyherbal formulation DiaKure were found to be within the limits as per I.P. which indicates the safety of the formulation. Data obtained from the study indicated that the content of heavy metals in the polyherbal formulation DiaKure was also found to be within the limits as per I.P. Since some of the individual herb contained antimicrobial activity, we screened the formulation for its antibacterial and anti-fungal activity. The antimicrobial sensitivity test has been completed by using six strains of micro organisms viz., two fungal species (Aspergillas and Penicillium) and four bacterial strains (streptococci, staphylococci, E.coli and Klebsciella) from both gram positive and gram negative groups, but the DiaKure did not show any activity against any of the species or, in other words, the zone of inhibition was completely absent. Hence, it is clear that the formulated drug DiaKure does not possess antimicrobial activity.

\section{CONCLUSION}

It was concluded from this study that the aqueous extract of DiaKure is rich in phytochemicals such as flavonoids, tannins, cardiac glycosides, alkaloids, saponins and steroids. These phytochemicals have been reported to be of pharmaceutical importance. This supports the use of this formulation in folklore medicine for the herbal treatment of diabetes. The extract and fractions of DiaKure used in this work revealed that the product does not possess any antimicrobial properties, heavy metal traces and pesticidal residues.

\section{ACKNOWLEDGEMENT}

We are thankful to all the staffs and students especially to Dr. CS Kandasamy, Mr. Jagadeesh, Mr. Senthil and Ms. Ashwini for their kind support and guidance. We also would like to thank all others who directly or indirectly gave a helping hand to us during this study.

\section{CONFLICT OF INTEREST}

The author declare no conflict of interest.

\section{ABBREVIATIONS USED}

DM: Diabetes mellitus; ECD: Electron capture detector; WHO: World Health Organization.

\section{ABOUT AUTHORS}

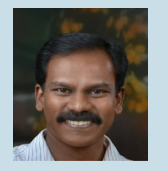

Sam Johnson Udaya Chander J: Completed M.Pharm (Pharmacy Practice) from The TN Dr. MGR Medical University, Tamil Nadu, India; and presently pursuing doctorate from the same university. Currently working as an Asst. Professor in the Dept. of Pharmacy Practice for RVS College of Pharmaceutical Sciences. Published more than 20 articles in both National and International journals.

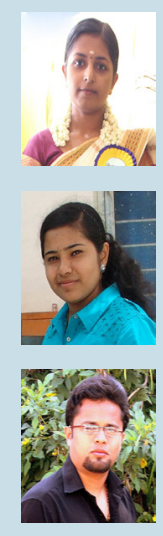

Ujawala TK: Completed Doctor of Pharmacy provisionally from The Tamilnadu Dr. MGR Medical University, Chennai. Currently working as an intern at KG Hospital and Postgraduate Research Institute. Has published many scientific articles both in international and national journals. Has presented scientific papers in different scientific conferences nationally.

Sandra Celine: Completed Doctor of Pharmacy provisionally from The Tamilnadu Dr. MGR Medical University, Chennai. Currently working as an intern at KG Hospital and Postgraduate Research Institute. Has published many scientific articles both in international and national journals. Has presented scientific papers in different scientific conferences nationally.

Shawn Tomy:Completed Doctor of Pharmacy provisionally from The Tamilnadu Dr. MGR Medical University, Chennai. Currently working as an intern at KG Hospital and Postgraduate Research Institute. Has published many scientific articles both in international and national journals. Has presented scientific papers in different scientific conferences nationally. 


\section{REFERENCES}

1. Ameenah Gurib-Fakim. Medicinal plants: Traditions of yesterday and drugs of tomorrow. Mol Aspects Med. 2006;27(1):1-93.

2. Barboza GE, Cantero JJ, Nunez C, Paccioroni A, Ariza-Espinar L. Medcinal plants - A general review and a phytochemical and ethnopharmacological screening of the native Argentina flora. Tomo 2009;34(1-2):7-365.

3. Parasuraman S, Thing GS, Dhanaraj SA. Polyherbal formulation: Concept of ayurveda. Pharmacogn Rev. 2014;8(16):73-80.

4. Steenkamp V. Phytomedicines for the prostate. Fitoterapia. 2003;74(6): 545-52.

5. Petchi RR, Vijaya C, Parasuraman S. Antidiabetic activity of polyherbal formulation in streptozotocin - nicotinamide induced diabetic wistar rats. J Tradit Complement Med. 2014;4(2):108-17.

6. Balunas MJ, Kinghorn AD. Drug discovery from medicinal plants. Life Sci. 2005;78(5): 431-41.

7. Venkatesh S, Reddy GD, Reddy BM, Ramesh M, Apparao AVN. Antihyperglycemic activity of Caralluma attenuate. Fitoterapia. 2003;74(3):274-279.

8. Sharma VK, Kumar S, Patel HJ, Hugar S. Hypoglycemic activity of Ficus glomerata in alloxan induced diabetic rats. International Int J Pharm Sci Rev Res. 2010;1(2):18-22.

9. Rajalakshmi M, Eliza J, Priya CE, Nirmala A, Daisy P. Antidiabetic properties of Tinospora cordifolia stem extracts on streptozotocin-induced diabetic rats. Afr $J$ Pharm Pharmacol. 2009;3(5):171-80.

10. Shanthi. A, R Radha, N Jayashree, R Selvaraj. Pharmacognostic validation of root of Hemidesmus indicus (Linn.). R Br J Chem Pharm Res. 2010;2(5):313-22.

11. Gawhare Vikesh S. Study of physicochemical properties of Indrayava (Holarrhena antidysenterica wall.) and its antibacterial effect on Enteropathogenic e-coli (EPEC) (in vitro). Int J Ayurvedic Med. 2013;4(2):113-21.

12. BC Patel, NM Patel. Standardization of 'Bhunimbadi Churna'-An Ayurvedic Polyherbal Formulation. IJPSR. 2013;4(10):4010-15.

13. Madhulika S, Ekta S. Preliminary Phytochemical Investigation of Berberis aristata, Acacia catechu and Ficus benghalensis- Important Medicinal Plants for Photoprotection. Int J Biol Pharm Res. 2013;4(9):614-7.

14. PH Rajasree, Vidya Vishwanad, Merin Cherian, Jincy eldhose, Ranjith Singh. Formulation and evaluation of antiseptic polyherbal ointment. Int J Pharm Life
Sci. 2012;3(10):1-10

15. Trease GE, Evans WC (1989) Textbook of Pharmacognosy. $12^{\text {th }}$ Edn. Balliere, Tinadl London.

16. Harborne JB. Phytochemical Methods - A Guide to Modern Techniques of Plant Analysis. Chapman and Hall, London. 1998pp. 182-90.

17. Kandasamy CS, Vidhya Sreenivasan, Gopal V, Arulraj P, Sam Johnson Udaya Chander, G Jeyabalan et al., Determination of Pesticidal Residues in the Hepatoprotective Polyherbal Formulation (RVSPHF567). EJBPS. 2015;2(4):455-60.

18. Moshi MJ, Mbwambo ZH, Kapingu MC, Mhozya VH, Marwa C. Antimicrobial and Brine Shrimp Lethality of extracts of Terminalia mollis Laws. Afri J Trad CAM 2006;3(3):1-10.

19. Wani MS. Herbal medicine and its standardization. Pharma info. 2007;1:1-6.

20. Indian Herbal Pharmacopoeia, Indian Drug Manufacturers' Association, Mumbai, 2002.

21. British Herbal Pharmacopoeia, British Herbal Medicine Association, 1996.

22. Quality Control Methods for Medicinal Plant Materials, WHO, Geneva, 1996.

23. Bhutani KK. Herbal medicines enigma and a challenge for science and guidelines for new initiatives. J Nat Prod. 2003;19(1):3-8.

24. Mosihuzzaman M, Choudhary MI. Protocols on safety, efficacy, standardization and documentation of herbal medicine. Pure Appl Chem. 2008;80(10):2195-230.

25. Seitz U, Bonn G, Oefner P, Popp M. Isotachophoretic analysis of flavonoids and phenolcarboxylic acids of relevance to phytopharmaceutical industry. J Chromatogr. 1991;559(1-2):499-504.

26. O'Shea TJ. Capillary electrophoresis/electrochemistry. Curr Sep. 1995;14(1):18-23.

27. Svicekova M, Havranek E, Novak V. Determination of heavy metals in samples of herbal drugs using differential pulse polarography. J Pharm Biol. 1993;42(2): 68-70.

28. Valiathan MS. Healing plants. Curr Sci. 1998;75:1122-6.

29. Issac RA, Johnson WC. Collaborative study of wet and dry ashing techniques for the elemental analysis of plant tissue by 'atomic absorption spectrophotometer. J. AOAC. 1975;58:436-40 